\title{
HUBUNGAN PENGETAHUAN DAN SIKAP IBU PASANGAN USIA SUBUR DENGAN PENGGUNAAN ALAT KONTRASEPSI DALAM RAHIM (AKDR) DI WILAYAH KERJA PUSKESMAS PANCUR BATU KABUPATEN DELI SERDANG TAHUN 2017
}

\author{
Honglianta R. Saragih \\ UPT Pelatihan Kesehatan SU \\ email : natassalaora@yahoo.co.id
}

\begin{abstract}
Abstrak
Salah satu alat jenis alat kontrasepsi yang memiliki efektivitas tinggi adalah Alat Kontrasepsi Dalam Rahim (AKDR). AKDR adalah cara pencegahan kehamilan yang sangat efektif, aman, dan reversibel bagi wanita dengan memasukkan kontrasepsi serviks dan dipasang di dalam uterus. Tujuan penelitian untuk mengetahui hubungan pengetahuan dan sikap ibu pasangan usia subur (PUS) dengan penggunaan AKDR di Wilayah Kerja (wilker) Puskesmas Pancur Batu Kabupaten Deli Serdang Tahun 2017. Jenis penelitian ini adalah analitik dengan pendekatan cross sectional. Populasi dalam penelitian ini adalah ibu PUS yang ada di wilker Puskesmas Pancur Batu Kabupaten Deli Serdang sebanyak 3852 orang pada bulan Juni 2017. Sampel dalam penelitian ini sebanyak 97 orang menggunakan purposive sampling dengan kriteria sampel. Analisis data dengan menggunakan data univariat dan bivariat. Hasil penelitian adalah pengetahuan ibu pasangan usia subur mayoritas terdapat pada kategori cukup yaitu 39 orang (40,2\%), sikap ibu PUS mayoritas terdapat pada kategori negatif yaitu 49 orang (50,5\%). Kesimpulan bahwa adanya hubungan pengetahuan dan sikap ibu PUS dengan penggunaan AKDR. Saran adalah diharapkan kepada petugas kesehatan agar meningkatkan promosi kesehatan tentang sosial demografi terkhususnya pada efek samping pemakaian AKDR sehingga akseptor mendapat informasi yang lengkap tentang AKDR dan cara penanggulangan efek samping yang berlebihan sehingga akseptor tetap menggunakan AKDR sebagai alat kontrasepsi jangka panjang yang efektif dan efesien.
\end{abstract}

Kata kunci : Pengetahuan, Sikap, Pasangan Usia Subur, AKDR

\section{PENDAHULUAN}

Program Safe Mother Hood meliputi keluarga berencana, persalinan yang aman, pelayanan antenatal, dan pelayanan obstetri esensial. Keluarga Berencana (KB) adalah salah satu gerakan untuk membentuk keluarga yang sehat sejahtera dengan membatasi jumlah kelahiran. Program KB bertujuan untuk menjarangkan kehamilan dengan menggunakan kontrasepsi. Metode-metode kontrasepsi yang ada di Indonesia saat ini meliputi Metode Amenore Laktasi (MAL), Keluarga Berencana Alamiah (KBA), kontrasepsi progestin, senggama terputus, metode barier, Alat Kontrasepsi Dalam Rahim (AKDR), kontrasepsi kombinasi, dan kontrasepsi mantap (Saifuddin. 2010)

Pasangan Usia Subur (PUS) dapat menentukan pilihan kontrasepsi sesuai dengan kondisi dan kebutuhannya berdasarkan informasi yang telah mereka pahami, termasuk keuntungan dan kerugian, risiko metode kontrasepsi dari petugas kesehatan. Program Keluarga Berencana $(\mathrm{KB})$ dilakukan diantaranya dalam rangka mengatur jumlah kelahiran atau menjarangkan kelahiran.
Sasaran program KB adalah Pasangan Usia Subur (PUS) yang lebih dititikberatkan pada kelompok Wanita Usia Subur (WUS) yang berada pada kisaran usia 15-49 tahun. Cakupan peserta KB baru menurut jenis kontrasepsi Tahun 2015 yaitu suntikan 49,93\%, pil 26,36\%, Implant 9,63, AKDR/IUD 6,81, kondom 5,47\%, MOW 1,64\% dan MOP $0,16 \%$. Cakupan peserta KB aktif menurut jenis kontrasepsi Tahun 2015 yaitu suntikan 47,78\%, pil 23,6\%, Implant 10,58, AKDR/IUD 10,73, kondom 3,16\%, MOW $3,49 \%$ dan MOP 0,65\%. Persentase peserta KB baru terhadap pasangan usia subur di Indonesia pada tahun 2015 sebesar 13,46\%. Angka ini lebih rendah dibandingkan capaian tahun 2014 yang sebesar 16,51\% (Kemenkes RI, 2016)

Salah satu alat jenis alat kontrasepsi yang memiliki efektivitas tinggi adalah Alat Kontrasepsi Dalam Rahim (AKDR). AKDR adalah cara pencegahan kehamilan yang sangat efektif, aman, dan reversibel bagi wanita (Pendit, 2014)

AKDR merupakan kontrasepsi yang dimasukkan melalui serviks dan dipasang di dalam uterus. AKDR mencegah kehamilan dengan merusak kemampuan hidup sperma dan ovum karena adanya perubahan pada tuba dan 
cairan uterus. Efektifitas AKDR dalam mencegah kehamilan mencapai $98 \%$ sampai $100 \%$ bergantung pada jenis AKDR. AKDR terbaru seperti copper T $380^{\circ}$ memiliki efekttivitas yang cukup tinggi bahkan selama 8 tahun penggunaan tidak ditemukan adanya kehamilan (Meilani, 2010)

Walaupun demikian, terdapat satu masalah utama yang dihadapi saat ini yaitu masih rendahnya penggunaan KB AKDR. Saat ini kurang lebih 85 juta wanita di seluruh dunia yang menggunakan AKDR dimana kira- kira $70 \%$ (59 juta) ada di RRC. Dari data yang dikumpulkan pada tahun 1982, tercatat 2,2 juta wanita akseptor KB AKDR di Amerika Serikat. Tetapi sejak tahun 1982, timbul sejumlah kejadian yang mengakibatkan penurunan jumlah akseptor KB AKDR (Angaraini, 2014)

Diperkirakan lebih dari 100 juta wanita yang memakai IUD, hampir 40\%-nya terdapat di Cina. Hanya $6 \%$ di negara maju dan $0.5 \%$ di sub-sahara Afrika. Pemakai IUD di Indonesia mencapai $22.6 \%$ dari semua pemakai metode kontrasepsi. Daya guna metode kontrasepsi merupakan faktor yang paling penting baik untuk klien (pasangan) yang memilih suatu metode kontrasepsi dan untuk pemberian pelayanan $\mathrm{KB}$ yang terlibat dalam konseling (Nawirah, 2016)

Rendahnya minat WUS terhadap AKDR tidak terlepas dari rendahnya pengetahuan terhadap alat kontrasepsi tersebut. Sehingga sangat perlu pemahaman yang baik tentang AKDR bagi wanita usia subur. Alat kontrasepsi dalam rahim merupakan salah satu metode kontrasepsi yang pengunaannya relatif lebih rendah dibandingkan dengan penggunaan metode kontrasepsi lain. Sikap wanita yang kurang berperan dalam pemeliharaan kesehatannya disebabkan oleh ketidak mengertian akan pentingnya dan cara-cara berperan dalam pemeliharaan kesehatan ibu dan anak termasuk KB. Hal tersebut tercermin dengan jelas dari adanya pola sikap tertentu terhadap AKDR dan kebiasaan masyarakat yang masih cenderung menyerahkan sepenuhnya tanggung jawab tersebut kepada para isteri (Pendit, 2014)

Berdasakan data yang diperoleh dari Wilayah Kerja Puskesmas Pancur Batu Kabupaten Deli Serdang bahwa jumlah ibu pasangan usia subur 3852 orang yang menjadi peserta KB aktif 752 orang. Dari 752 peserta KB aktif yang menggunakan Alat Kontrasepsi Dalam Rahim (AKDR) sebanyak 38 orang yang pernah drop out dari Alat Kontrasepsi Dalam Rahim (AKDR) sebanyak 12 orang. Survei awal yang dilakukan peneliti dengan $10 \mathrm{ibu}$ pasangan usia subur bahwa terdapat 3 orang ibu tidak mengetahui AKDR, 1 orang ibu tidak mengetahui jenis AKDR, 2 orang ibu tidak mengetahui tentang keuntungan dan kerugian menggunakan AKDR, 2 orang ibu tidak mengetaui persyaratan penggunaan AKDR, 1 orang mengatakan tidak cocok menggunakan AKDR karena takut atau khawatir AKDR dan 2 orang mengatakan takut menggunakan AKDR karena mendengar rumor yang beredar di masyarakat tentang AKDR bahwa AKDR dapat tertanam di dalam rahim dan dapat menyebabkan kanker. Berdasarkan latar belakang, penulis tertarik meneliti tentang hubungan pengetahuan dan sikap ibu pasangan usia subur dengan penggunaan Alat Kontrasepsi Dalam
Rahim (AKDR) di Wilayah Kerja Puskesmas Pancur Batu Kabupaten Deli Serdang Tahun 2017.

\section{Rumusan Masalah}

Berdasarkan latar belakang yang diuraikan diatas maka rumusan masalah adalah bagaimana mengetahui bagaimana hubungan pengetahuan dan sikap ibu pasangan usia subur dengan penggunaan Alat Kontrasepsi Dalam Rahim (AKDR) di Wilayah Kerja Puskesmas Pancur Batu Kabupaten Deli Serdang Tahun 2017.

\section{Tujuan Penelitian}

a. Untuk mengetahui penggunaan Alat Kontrasepsi Dalam Rahim (AKDR) di Wilayah Kerja Puskesmas Pancur Batu Kabupaten Deli Serdang Tahun 2017

b. Untuk mengetahui pengetahuan ibu pasangan usia subur dengan penggunaan Alat Kontrasepsi Dalam Rahim (AKDR) di Wilayah Kerja Puskesmas Pancur Batu Kabupaten Deli Serdang Tahun 2017

c. Untuk mengetahui sikap ibu pasangan usia subur dengan penggunaan Alat Kontrasepsi Dalam Rahim (AKDR) di Wilayah Kerja Puskesmas Pancur Batu Kabupaten Deli Serdang Tahun 2017

d. Untuk mengetahui hubungan pengetahuan dan sikap ibu pasangan usia subur dengan penggunaan Alat Kontrasepsi Dalam Rahim (AKDR) di Wilayah Kerja Puskesmas Pancur Batu Kabupaten Deli Serdang Tahun 2017

\section{Manfaat}

a. Bagi Tenaga Kesehatan Sebagai masukan dalam upaya pemberian konseling kepada calon akseptor khususnya akseptor KB yang tidak menggunakan kontrasepsi AKDR agar dapat menerima alat kontrasepsi AKDR

b. Bagi Responden

Dapat menambah pengetahuan dan wawasan ibu akseptor KB tentang kontrasepsi AKDR

c. Bagi Peneliti Selanjutnya

Sebagai sumber data atau masukan bagi penelitian selanjutnya yang berhubungan dengan Alat Kontrasepsi Dalam Rahim (AKDR)

\section{METODE}

Jenis penelitian ini adalah penelitian survei yang bersifat analitik dengan menggunakan desain sekat silang (cross sectional) untuk mengetahui hubungan pengetahuan dan sikap ibu pasangan usia subur dengan penggunaan Alat Kontrasepsi Dalam Rahim (AKDR) di Wilayah Kerja Puskesmas Pancur Batu Kabupaten Deli Serdang Tahun 2017. Pemilihan lokasi ini karena menurut survei awal peneliti bahwa jumlah ibu pasangan usia subur yang ada di Wilayah Kerja Puskesmas Pancur Batu Kabupaten Deli 
Serdang sebanyak 3852 orang pada bulan Juni 2017, dan dari 752 peserta KB aktif yang menggunakan Alat Kontrasepsi Dalam Rahim (AKDR) sebanyak 38 orang yang pernah drop out dari Alat Kontrasepsi Dalam Rahim (AKDR) sebanyak 12 orang. Teknik pengambilan sampel adalah dengan menggunakan rumus Slovin dalam Notoatmodjo (2010). ${ }^{13}$ Jadi, besar sampel yang diambil 97 orang. Pengambilan sampel diambil dengan cara acak sederhana (simple random sampling). Aspek Pengukuran Variabel Dependen dan Independen yang digunakan adalah :

\begin{tabular}{|c|c|c|c|c|}
\hline No & Variabel & $\begin{array}{l}\text { Cara dan } \\
\text { Alat Ukur }\end{array}$ & $\begin{array}{c}\text { Skala } \\
\text { Pengukuran }\end{array}$ & $\begin{array}{c}\text { Jenis Skala } \\
\text { Ukur }\end{array}$ \\
\hline 1 & Pengetahuan & $\begin{array}{c}\text { Kuesioner } \\
10 \\
\text { pertanyaan }\end{array}$ & 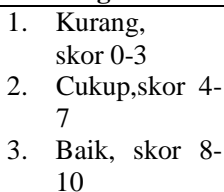 & Ordinal \\
\hline 2 & Sikap & $\begin{array}{c}\text { Kuesioner } \\
10 \\
\text { pertanyaan }\end{array}$ & $\begin{array}{l}\text { 1. } \begin{array}{l}\text { Negatif, } \\
\text { skor } 10-25\end{array} \\
\text { 2. Positif, } \\
\text { skor } 26-40\end{array}$ & Ordinal \\
\hline 3 & $\begin{array}{l}\text { Penggunaan } \\
\text { Alat } \\
\text { Kontrasepsi } \\
\text { Dalam } \\
\text { Rahim } \\
\text { (AKDR) }\end{array}$ & $\begin{array}{c}\text { Kuesioner, } \\
1 \\
\text { pernyataan }\end{array}$ & $\begin{array}{l}\text { 1. Tidak } \\
\text { menggunakan } \\
\text { AKDR } \\
\text { 2. Menggunakan } \\
\text { AKDR }\end{array}$ & Ordinal \\
\hline
\end{tabular}

Analisa data menggunakan univariate dan bivariate.

\section{HASIL}

1. Umur

Tabel 1. Distribusi Frekuensi Umur Ibu Pasangan Usia Subur di Wilayah Kerja Puskesmas Pancur Batu Kabupaten Deli Serdang Tahun 2017

\begin{tabular}{cccc}
\hline No. & Umur & Frekuensi & $\begin{array}{c}\text { Persentase } \\
(\mathbf{\%})\end{array}$ \\
\hline 1. & $<20$ tahun & 8 & 8,2 \\
\hline 2. & $21-35$ tahun & 30 & 30,9 \\
\hline 3. & $>36$ tahun & 59 & 60,8 \\
\hline & Jumlah & $\mathbf{9 7}$ & $\mathbf{1 0 0 , 0}$ \\
\hline
\end{tabular}

Dari tabel 1. diatas bahwa umur ibu pasangan usia subur $<20$ tahun yaitu 8 orang $(8,2 \%), 21-35$ tahun yaitu 30 orang $(30,9 \%)$ dan $>36$ tahun yaitu 59 orang $(60,8 \%)$

\section{Pendidikan}

Tabel 2. Distribusi Frekuensi Pendidikan Ibu Pasangan Usia Subur di Wilayah Kerja Puskesmas Pancur Batu Kabupaten Deli Serdang Tahun 2017

\begin{tabular}{clcc}
\hline No & Pendidikan & Frekuensi & $\begin{array}{c}\text { Persentase } \\
(\mathbf{\%})\end{array}$ \\
\hline 1. & Dasar & 12 & 12,4 \\
\hline 2. & Menengah & 55 & 56,7 \\
\hline 3. & Tinggi & 30 & 30,9 \\
\hline & Jumlah & $\mathbf{9 7}$ & $\mathbf{1 0 0 , 0}$ \\
\hline
\end{tabular}

Dari tabel 2. diatas bahwa pendidikan ibu pasangan usia subur kategori dasar yaitu 12 orang $(12,4 \%)$, menengah yaitu 55 orang $(56,7 \%)$ dan tingi yaitu 30 orang $(30,9 \%)$.

\section{Jumlah Anak}

Tabel 3. Distribusi Frekuensi Jumlah Anak Ibu Pasangan Usia Subur di Wilayah Kerja Puskesmas Pancur Batu Kabupaten Deli Serdang Tahun 2017

\begin{tabular}{cccc}
\hline No & Jumlah Anak & Frekuensi & $\begin{array}{c}\text { Persentase } \\
(\mathbf{\%})\end{array}$ \\
\hline 1. & $\leq 2$ anak & 34 & 35,1 \\
\hline 2. & $>2$ anak & 63 & 64,9 \\
\hline & Jumlah & $\mathbf{9 7}$ & $\mathbf{1 0 0 , 0}$ \\
\hline
\end{tabular}

Dari tabel 3. diatas bahwa jumlah anak ibu pasangan usia subur mayoritas kategori $\leq 2$ anak yaitu 34 orang $(35,1 \%)$ dan $>2$ anak yaitu 63 orang $(64,9 \%)$.

4. Pengetahuan Ibu Pasangan Usia Subur

Tabel 4. Distribusi Frekuensi Pengetahuan Ibu Pasangan Usia Subur di Wilayah Kerja Puskesmas Pancur Batu Kabupaten Deli Serdang Tahun 2017

No. Pengetahuan Frekuensi Persentase

\begin{tabular}{clcc} 
& & & $\mathbf{( \% )}$ \\
\hline 1. & Kurang & 33 & 34,0 \\
\hline 2. & Cukup & 39 & 40,2 \\
\hline 3. & Baik & 25 & 25,8 \\
\hline & Jumlah & $\mathbf{9 7}$ & $\mathbf{1 0 0 , 0}$ \\
\hline
\end{tabular}

Dari tabel 4. diatas bahwa pengetahuan ibu pasangan usia subur pada kategori kurang cukup yaitu 33 orang $(34,0 \%)$, cukup yaitu 39 orang $(40,2 \%)$ dan baik yaitu 25 orang $(25,8 \%)$.

\section{Sikap Ibu Pasangan Usia Subur}

Tabel 5. Distribusi Frekuensi Sikap Ibu Pasangan Usia Subur di Wilayah Kerja Puskesmas Pancur Batu Kabupaten Deli Serdang Tahun 2017

\begin{tabular}{cccc}
\hline No. & Sikap & Frekuensi & Persentase (\%) \\
\hline 1. & Negatif & 49 & 50,5 \\
\hline 2. & Positif & 48 & 49,5 \\
\hline & Jumlah & $\mathbf{9 7}$ & $\mathbf{1 0 0 , 0}$ \\
\hline
\end{tabular}

Dari tabel 5. diatas bahwa sikap ibu pasangan usia subur kategori negatif yaitu 49 orang $(50,5 \%)$ dan positif yaitu 48 orang $(49,5 \%)$. 
6. Penggunaan Alat Kontrasepsi Ibu Pasangan Usia Subur

Tabel 6. Distribusi Frekuensi Penggunaan Alat Kontrasepsi Ibu Pasangan Usia Subur di Wilayah Kerja Puskesmas Pancur Batu Kabupaten Deli Serdang Tahun 2017

\begin{tabular}{clcc}
\hline No. & $\begin{array}{l}\text { Penggunaan Alat } \\
\text { Kontrasepsi }\end{array}$ & Frekuensi & $\begin{array}{c}\text { Persentase } \\
(\mathbf{\%})\end{array}$ \\
\hline 1. & $\begin{array}{l}\text { Tidak menggunakan } \\
\text { kontrasepsi }\end{array}$ & 24 & 24,7 \\
\hline 2. & Kondom & 16 & 16,5 \\
\hline 3. & Pil & 19 & 19,6 \\
\hline 4. & Suntik & 13 & 13,4 \\
\hline 5. & Implant & 3 & 3,1 \\
\hline 6. & AKDR & 17 & 17,5 \\
\hline 7. & MOW & 5 & 5,2 \\
\hline & Jumlah & $\mathbf{9 7}$ & $\mathbf{1 0 0 , 0}$ \\
\hline
\end{tabular}

Dari tabel 6. diatas bahwa penggunaan alat kontrasepsi ibu pasangan usia subur kategori tidak menggunakan kontrasepsi yaitu 24 orang $(24,7 \%)$, kondom yaitu 16 orang $(16,5 \%)$, pil yaitu 19 orang $(19,6 \%)$, suntik yaitu 13 orang $(13,4 \%)$, implant yaitu 3 orang $(13,4 \%)$, AKDR yaitu 17 orang $(17,5 \%)$ dan MOW yaitu 5 orang $(5,2 \%)$

\section{Penggunaan AKDR}

Tabel 7. Distribusi Frekuensi Penggunaan AKDR Ibu Pasangan Usia Subur di Wilayah Kerja Puskesmas Pancur Batu Kabupaten Deli Serdang Tahun 2017

\begin{tabular}{clcc}
\hline No. & \multicolumn{1}{c}{$\begin{array}{c}\text { Penggunaan } \\
\text { AKDR }\end{array}$} & Frekuensi & $\begin{array}{c}\text { Persentase } \\
(\mathbf{\%})\end{array}$ \\
\hline 1. & $\begin{array}{l}\text { Tidak } \\
\text { menggunakan } \\
\text { AKDR }\end{array}$ & 80 & 82,5 \\
\hline 2. & $\begin{array}{l}\text { Menggunakan } \\
\text { AKDR }\end{array}$ & 17 & 17,5 \\
\hline \multicolumn{1}{c}{ Jumlah } & $\mathbf{9 7}$ & $\mathbf{1 0 0 , 0}$ \\
\hline
\end{tabular}

Dari tabel 7. diatas bahwa penggunaan AKDR ibu pasangan usia subur kategori tidak menggunakan AKDR yaitu 80 orang $(82,5 \%)$ dan menggunakan AKDR yaitu 17 orang $(17,5 \%)$.

8. Hubungan Pengetahuan Ibu Pasangan Usia Subur Dengan Penggunaan Alat Kontrasepsi Dalam Rahim (AKDR)

Tabel 8. Distribusi Tabulasi Silang Hubungan Pengetahuan Ibu Pasangan Usia Subur Dengan Penggunaan Alat Kontrasepsi Dalam Rahim (AKDR) di Wilayah Kerja Puskesmas Pancur Batu Kabupaten Deli Serdang Tahun 2017

\begin{tabular}{|c|c|c|c|c|c|c|c|c|}
\hline \multirow{3}{*}{ No } & \multirow{3}{*}{$\begin{array}{c}\text { Pengetahu } \\
\text { an Ibu } \\
\text { PUS }\end{array}$} & \multicolumn{4}{|c|}{ Penggunaan AKDR } & \multicolumn{2}{|c|}{ Jumlah } & \multirow[t]{2}{*}{ p value } \\
\hline & & \multicolumn{2}{|c|}{$\begin{array}{c}\text { Tidak } \\
\text { menggunaka } \\
\text { n AKDR }\end{array}$} & \multicolumn{2}{|c|}{$\begin{array}{c}\text { Menggunak } \\
\text { an AKDR }\end{array}$} & & & \\
\hline & & $\mathbf{f}$ & $\%$ & $\mathbf{f}$ & $\%$ & $\mathbf{f}$ & $\%$ & 0,001 \\
\hline 1 & Kurang & 32 & 33,0 & 1 & 1,0 & 33 & 34,0 & \\
\hline 2 & Cukup & 33 & 34,0 & 6 & 6,2 & 39 & 40,2 & \\
\hline 3 & Baik & 15 & 15,5 & 10 & 10,3 & 25 & 25,8 & \\
\hline & Jumlah & 80 & 82,5 & 17 & 17,5 & 97 & 100 & \\
\hline
\end{tabular}

Dari tabel 8. diatas bahwa pengetahuan ibu pasangan usia subur mayoritas dengan kategori cukup yaitu 33 orang $(34,0 \%)$ dengan penggunaan Alat Kontrasepsi Dalam Rahim (AKDR) kategori tidak menggunakan AKDR yaitu 33 orang $(34,0 \%)$ dan menggunakan AKDR yaitu 6 orang $(6,2 \%)$. Berdasarkan hasil uji chi square dengan nilai signifikansi yaitu $0,001<$ 0,05, maka Ho ditolak dan Ha diterima. Kesimpulannya ada hubungan pengetahuan ibu pasangan usia subur dengan penggunaan Alat Kontrasepsi Dalam Rahim (AKDR) di Wilayah Kerja Puskesmas Pancur Batu Kabupaten Deli Serdang Tahun 2017.

9. Hubungan Sikap Ibu Pasangan Usia Subur Dengan Penggunaan Alat Kontrasepsi Dalam Rahim (AKDR)

Tabel 9. Distribusi Tabulasi Silang Hubungan Sikap Ibu Pasangan Usia Subur Dengan Penggunaan Alat Kontrasepsi Dalam Rahim (AKDR) di Wilayah Kerja Puskesmas Pancur Batu Kabupaten Deli Serdang Tahun 2017

\begin{tabular}{ccccccccc}
\hline & & \multicolumn{2}{c}{ Penggunaan AKDR } & Jumlah & p value \\
\cline { 3 - 7 } No & $\begin{array}{c}\text { Sikap Ibu } \\
\text { PUS }\end{array}$ & $\begin{array}{c}\text { Tidak } \\
\text { menggunak } \\
\text { an AKDR }\end{array}$ & $\begin{array}{c}\text { Menggunak } \\
\text { an AKDR }\end{array}$ & & & \\
\cline { 3 - 7 } & & f & \% & f & \% & f & \% & 0,003 \\
\cline { 3 - 7 } 1 & Negatif & 46 & 47,4 & 3 & 3,1 & 49 & 50,5 & \\
\hline 2 & Positif & 34 & 35,1 & 14 & 14,4 & 48 & 49,5 & \\
\hline & Jumlah & $\mathbf{8 0}$ & $\mathbf{8 2 , 5}$ & $\mathbf{1 7}$ & $\mathbf{1 7 , 5}$ & $\mathbf{9 7}$ & $\mathbf{1 0 0}$ & \\
\hline
\end{tabular}

Dari tabel 9. diatas bahwa sikap ibu pasangan usia subur mayoritas dengan kategori negatif yaitu 49 orang $(50,5 \%)$ dengan penggunaan Alat Kontrasepsi Dalam Rahim (AKDR) kategori tidak menggunakan AKDR yaitu 46 orang $(47,4 \%)$ dan menggunakan AKDR yaitu 3 orang $(3,1 \%)$. Berdasarkan hasil uji chi square dengan nilai signifikansi yaitu $0,003<0,05$, maka Ho ditolak dan Ha diterima. Kesimpulannya ada hubungan sikap ibu pasangan usia subur dengan penggunaan Alat Kontrasepsi Dalam Rahim (AKDR) di Wilayah Kerja Puskesmas Pancur Batu Kabupaten Deli Serdang Tahun 2017.

\section{PEMBAHASAN}

1. Hubungan Pengetahuan Ibu Pasangan Usia Subur Dengan Penggunaan Alat Kontrasepsi Dalam Rahim (AKDR)

Hasil penelitian bahwa pengetahuan ibu pasangan usia subur mayoritas dengan kategori cukup yaitu 33 orang $(34,0 \%)$ dengan penggunaan Alat Kontrasepsi Dalam Rahim (AKDR) kategori tidak menggunakan AKDR yaitu 33 orang $(34,0 \%)$ dan menggunakan AKDR yaitu 6 orang $(6,2 \%)$. Berdasarkan hasil uji chi square dengan nilai signifikansi yaitu $0,001<0,05$, maka Ho ditolak dan $\mathrm{Ha}$ diterima. Kesimpulannya ada hubungan pengetahuan ibu pasangan usia subur dengan penggunaan Alat Kontrasepsi Dalam Rahim (AKDR) di Wilayah Kerja Puskesmas Pancur Batu Kabupaten Deli Serdang Tahun 2017 
Penelitian Henry (2013) bahwa ada hubungan pengetahuan dengan pemilihan kontrasepsi IUD pada wanita usia subur di Desa Sepanjang Wilayah Kerja Puskesmas Sepanjang Kecamatan Glenmore Kabupaten Banyuwangi. Responden dengan pengetahuan baik sebanyak 66 orang, sebagian besar tidak memilih kontra sepsi IUD. Untuk responden dengan tingkat pengetahuan cukup sebanyak 106 orang, sebagian besar tidak memilih kontra sepsi IUD. Sementara itu untuk responden dengan tingkat pengetahuan kurang sebanyak 106 orang, sebagian besar memilih kontrasepsi IUD

Rendahnya penggunaan AKDR salah satunya dipengaruhi kurangnya pengetahuan aseptor tentang kelebihan dari metode kontrasepsi AKDR dan lebih mengetahui efek samping dari AKDR. Padahal metode AKDR juga memiliki kelebihan yaitu pengguna tidak harus datang ke pelayanan kesehatan setiap bulan untuk mengganti alat kontrasepsi tersebut sehingga lebih efisien terutama bagi ibu yang sering lupa, pengembalian masa kesuburan bagi pengguna cukup tinggi, serta praktis, dapat digunakan sampai menopause, tidak mempengaruhi volume dan kualitas ASI. Metode ini memiliki efek samping yaitu dapat menyebabkan peningkatan darah mentruasi, pada saat pemasangan juga menimbulkan rasa takut bagi ibu, dapat menyebabkan penyakit radang panggul, terdapat komplikasi dapat merasakan kejang selama 3-5 hari setelah pemasangan (Affandi, 2011)

Kurang berhasilnya program KB diantaranya dipengaruhi oleh tingkat pengetahuan ibu dan faktor pendukung lainnya. Untuk mempunyai sikap yang positif tentang $\mathrm{KB}$ diperlukan pengetahuan yang baik, demikian sebaliknya bila pengetahuan kurang maka kepatuhan menjalani program KB berkurang. ibu yang mempunyai pengetahuan tinggi memiliki kemungkinan 2 kali lebih besar untuk menggunakan MKJP (metode AKDR) dibandingkan dengan ibu yang berpengetahuan rendah, namun belum tentu ibu yang berpengetahuan baik memilih metode AKDR karena ibu tersebut sudah mengetahui cara pemasangan, efek samping dan lain sebagainya.

Asumsi peneliti bahwa ada hubungan pengetahuan ibu pasangan usia subur dengan penggunaan Alat Kontrasepsi Dalam Rahim (AKDR). Kurangnya pengetahuan pada calon akseptor sangat berpengaruh terhadap pemakaian kontrasepsi AKDR meskipun responden berpengetahuan cukup, tetapi responden tidak mau ikut serta menjadi akseptor AKDR. Seharusnya responden yang memiliki pengetahuan cukup mau ikut serta menjadi akseptor AKDR. Alasan responden tidak ikut menjadi akseptor AKDR karena sikap negatif ibu terhadap kontrasepsi AKDR

\section{Hubungan Sikap Ibu Pasangan Usia Subur Dengan Penggunaan Alat Kontrasepsi Dalam Rahim (AKDR)}

Hasil penelitian bahwa sikap ibu pasangan usia subur mayoritas dengan kategori negatif yaitu 49 orang
(50,5\%) dengan penggunaan Alat Kontrasepsi Dalam Rahim (AKDR) kategori tidak menggunakan AKDR yaitu 46 orang $(47,4 \%)$ dan menggunakan AKDR yaitu 3 orang $(3,1 \%)$. Berdasarkan hasil uji chi square dengan nilai signifikansi yaitu $0,003<0,05$, maka Ho ditolak dan Ha diterima. Kesimpulannya ada hubungan sikap ibu pasangan usia subur dengan penggunaan Alat Kontrasepsi Dalam Rahim (AKDR) di Wilayah Kerja Puskesmas Pancur Batu Kabupaten Deli Serdang Tahun 2017

Hal ini sejalan dengan penelitian Ari (2016) responden mempunyai sikap mendukung yang memilih AKDR sebanyak 13 responden (93\%) yang tidak memilih sebanyak 58 responden $(41,5 \%)$. Responden mempunyai sikap tidak mendukung memilih AKDR sebanyak 4 responden $(2,8 \%)$, dan yang tidak mendukung dan tidak memilih sebanyak 65 responden $(46,4 \%)$. Terdapat hubungan antara sikap ibu dengan pemilihan AKDR.

Asumsi peneliti bahwa ada hubungan sikap ibu pasangan usia subur dengan penggunaan Alat Kontrasepsi Dalam Rahim (AKDR). Mayoritas responden memiliki sikap yang negatif terhadap kontrasepsi AKDR sehingga banyak akseptor KB yang tidak mau menggunakan kontrasepsi AKDR. Sikap dan keyakinan merupakan kunci penerimaan KB. Banyak sikap yang dapat menghalangi $\mathrm{KB}$ dan penggunaan suatu alat kontrasepsi. Banyak ibu bersikap negatif terhadap alat kontrasepsi AKDR. Hal ini karena sering mendengar rumor/ mitos yang beredar di masyarakat, misalnya rumor tentang AKDR yang dapat berpindahpindah tempatnya dan hilang, dapat menyebabkan kanker.

\section{Simpulan}

a. Ada hubungan pengetahuan ibu pasangan usia subur dengan penggunaan Alat Kontrasepsi Dalam Rahim (AKDR) di Wilayah Kerja Puskesmas Pancur Batu Kabupaten Deli Serdang Tahun 2017 dengan nilai signifikansi yaitu $0,001<0,05$

b. Ada hubungan sikap ibu pasangan usia subur dengan penggunaan Alat Kontrasepsi Dalam Rahim (AKDR) di Wilayah Kerja Puskesmas Pancur Batu Kabupaten Deli Serdang Tahun 2017 dengan nilai signifikansi yaitu 0,003 $<0,05$.

\section{Saran}

a. Bagi Puskesmas Tanjung Selamat Kabupaten Langkat

Diharapkan kepada Petugas Kesehatan Wilayah Kerja Puskesmas Pancur Batu Kabupaten Deli Serdang agar meningkatkan promosi kesehatan tentang sosial demografi terkhususnya pada efek samping pemakaian AKDR sehingga akseptor AKDR mendapat informasi yang lengkap tentang AKDR dan cara penanggulangan efek samping yang berlebihan sehingga akseptor AKDR tetap menggunakan AKDR sebagai alat kontrasepsi jangka panjang yang efektif dan efesien 
b. Bagi Responden

Diharapkan untuk ibu akseptor KB dapat menambah pengetahuannya dari berbagai sumber informasi tentang AKDR dan dapat memilih alat kontrasepsi yang memiliki efektivitas yang tinggi dan memiliki angka kegagalan yang rendah, terutama bagi ibu yang sudah mempunyai 2 orang anak.

c. Bagi peneliti

Dapat menambah pengalaman bagi penulis dalam mengaplikasikan ilmu yang telah di dapat dalam memberikan pelayanan kepada masyarakat, serta sebagai masukan akan pengetahuan tentang kontrasepsi AKDR

d. Bagi Peneliti Selanjutnya

Peneliti selanjutnya diharapkan dalam melakukan penelitian dapat menggunakan teknik wawancara secara langsung dan menambah jumlah sampel sehingga dapat menghasilkan penelitian yang memiliki kualitas lebih baik

\section{DAFTAR PUSTAKA}

Angaraini, Yetti dan Martini. Pelayanan Keluarga Berencana. Yogjakarta: Rohima Press. 2012.

Affandi, B. Buku Panduan Praktis Pelayanan Kontrasepsi. Edisi 3. Jakarta: PT. Bina Pustaka Sarwono Prawirohardjo. 2011.

Ari Antini. Hubungan Pengetahuan, Sikap dan Budaya Akseptor KB Terhadap Pemilihan Metode Akdrdi Wilayah Kerja Puskesmas Anggadita Kabupaten Karawang. 2016. [Jurnal Internet]. Tersedia dari download.portalgaruda. org/article.php?...HUBUNGAN\%20\%20PE...Tra nslate this page. [Diakses tanggal 1 Agustus 2017]

Henry Sutanti. Hubungan Pengetahuan dan Sikap Dengan Pemilihan Kontrasepsi IUD Pada Wanita Usia Subur di Desa Sepanjang Wilayah Kerja Puskesmas Sepanjang Kabupaten Banyuwangi. 2013. [Jurnal Internet]. Tersedia dari e- journal.akesrustida.ac.id/folder.../201505

11014623pecah04.pdf Translate this page. [Diakses tanggal 17 Juli 2017]

Kementerian Republik Indonesia, 2016. Profil Kesehatan Indonesia Tahun 2015. [Jurnal Internet]. Tersedia dari www.depkes.go.id /resources/download/...indonesia/profilkesehatan-Indonesia-2015.pdf. [Diakses tanggal 16 Juni 2017]. Hal 150-151

Meilani dkk. Pelayanan Keluarga Berencana (Dilengkapi dengan Penuntun Belajar), Penerbit Fitramaya, Yogyakarta. 2010.

Nawirah. Faktor Yang Mempengaruhi Pemilihan Kontrasepsi IUD di Wilayah Kerja Puskesmas Wonomulyo Kecamatan Wonomulyo Kabupaten Polman. 2016. [Jurnal Internet]. Tersedia dari repository.unhas.ac.id /.../NAWIRAH\%20K11112605.pdf?sequenc... Translate this page. [Diakses tanggal 17 Juli 2017].

Pendit. Ragam Metode Kontrasepsi, Penerbit Buku Kedokteran EGC, Jakarta. 2014.

Saifuddin. 2010. Buku Panduan Praktis Pelayanan Kontrasepsi. Yayasan Bina Pustaka Sarwono Prawiroharjo. Jakarta. 2010. 